\title{
Laser induced injury caused hyperglycemia-like effect in Drosophila larva: a possible insect model for posttraumatic diabetes
}

\author{
Fumio OKABE ${ }^{1)}$, Yoko NAKAGIRI ${ }^{1)}$, Takahisa YAMADA ${ }^{2)}$ and Hiroyuki KOSE ${ }^{1) *}$ \\ 1)Department of Life Science, Division of Natural Sciences, International Christian University, Mitaka, Tokyo 181-8585, Japan \\ ${ }^{2)}$ Laboratory of Animal Genetics, Graduate School of Science and Technology, Niigata University, Niigata 950-2181, Japan
}

(Received 1 December 2014/Accepted 7 January 2015/Published online in J-STAGE 23 January 2015)

ABSTRACT. Diabetic patients need particular care in case of infection, digestive disorder or external injury, because external stress often exasperates the glucose metabolism, which is known as "sick day management". In addition, severe trauma can be a cause of hyperglycemia with insulin resistance. In spite of critical component of the treatment, the precise mechanisms of how trauma develops posttraumatic diabetes remain unknown. Here, we ablated body wall muscles in Drosophila larvae by laser beam and found that the level of trehalose, the principal sugar circulating in the hemolymph or in the tissues of most insects, was increased. The model may provide a helpful tool to understand the relationship between trauma and sugar metabolism.

KEY WOEDS: animal model, Drosophila, metabolism, posttraumatic diabetes

doi: 10.1292/jvms.14-0631; J. Vet. Med. Sci. 77(5): 601-604, 2015

It has been recognized for decades that severe stress, such as trauma, systemic infection and surgery, triggers the hypermetabolic response or stress hyperglycemia [21, 25, 26, 29]. In clinical practice, special attention is required for diabetes patients in case of infection or injury, commonly known as "sick day management" [4]. Furthermore, admission glucose of trauma patient can be a prognostic indicator for mortality rate $[6,31]$. Although mild-stress hyperglycemia is considered a critical survival response and protective against injection by providing a source of fuel for the immune system [14], in many cases, chronic endocrine responses lead to persistent hyperglycemia and insulin resistance [28].

Several animal studies as well as studies on patients revealed that trauma stimulates the secretion of inflammatory cytokines, like TNF, IL-1 and IL-6, as well as glucagon, cortisol and catecholamine $[5,13,15,16]$, which may directly mediate the hyperglycemia. Furthermore, phosphorylation of Ser307 in IRS-1, a common indicator of insulin resistance, is significantly elevated in the burn-injured mice [32]. However, the precise mechanisms for insulin resistance produced by burns or other stressor remain largely unknown.

In recent years, the number of investigations into metabolism using Drosophila has sharply increased [11, 20]. Drosophila genome encodes insulin/glucagon homologues as well as leptin equivalent gene, and most of the signaling components are conserved $[12,21,23]$. Here, we set out to establish a novel model of "diabetes of injury" in Drosophila, which will allow us to take advantage of fly genetics to gain

*Correspondence to: Kose, H., Department of Life Science, Division of Natural Sciences, International Christian University, Mitaka, Tokyo 181-8585, Japan. e-mail: kose@icu.ac.jp

(C)2015 The Japanese Society of Veterinary Science

This is an open-access article distributed under the terms of the Creative Commons Attribution Non-Commercial No Derivatives (by-nc-nd) License $<$ http://creativecommons.org/licenses/by-nc-nd/3.0/>. insight into its mechanisms. We evaluated metabolisms by measuring trehalose, instead of glucose, because it is a disaccharide composed of two glucose molecules and is the principal blood sugar in many insects. All fly stocks were reared at $25^{\circ} \mathrm{C}$ on a standard yeast, corn meal and agar medium, under $12 \mathrm{hr}: 12 \mathrm{hr}$ light:dark conditions unless otherwise stated. The following fly stocks were used: 5053A-Gal4 (DGRC number 107443) [22], NP6310 (DGRC number 113906) [9] and UAS-2XEGFP AH2 (FBst0006874). The laser lesioning of muscle fibers was done in the second instar larvae.

Drosophila larvae body wall muscles consisted of about 580 muscle fibers, each of which can be distinguished from its neighbors by its size, shape and attachment sites [1]. In order to target specific fibers, 5053A-Ga4 strain was chosen to mark, among 30 muscle fibers in each of hemisegments of A2-A7, one particular fibers called ventrolateral body wall muscle 12 (VLM12) (Fig. 1A) [18, 22]. Ablation of muscle fibers was performed as follows: The larvae were anesthetized with ether and immersed in silicon oil (ShinEtsu Chemical Co., Tokyo, Japan, FL-100) beneath a coverslip. Muscle fibers were identified using GFP fluorescent signal and Nomarski optics. The muscle fiber was lesioned by directing a series of $3.5 \mathrm{nsec}$ laser pulses with a peak power of $170 \mu \mathrm{J}$ at $440 \mathrm{~nm}$, generated by a MicroPoint dye laser system (Photonic Instruments Co., Kawasaki, Japan). After muscles were lesioned, the larvae were transferred to grape juice plate supplemented with a thin layer of yeast paste and incubated for $24 \mathrm{hr}$ at $24^{\circ} \mathrm{C}$ before proceeding to the metabolic measurements. For sham control, the larvae were anesthetized, immersed in silicon oil and allowed to stay under a coverslip for $8 \mathrm{~min}$, which is an average period of time required for lesioning. Trehalose and protein levels were assayed as follows: Whole-larvae treharose was measured by Trehalose Assay Kit (Megazyme, Wicklow, Ireland, K-TREH). For whole-fly preparation, 5 larvae were collected and briefly rinsed in Ringer's solution. The 

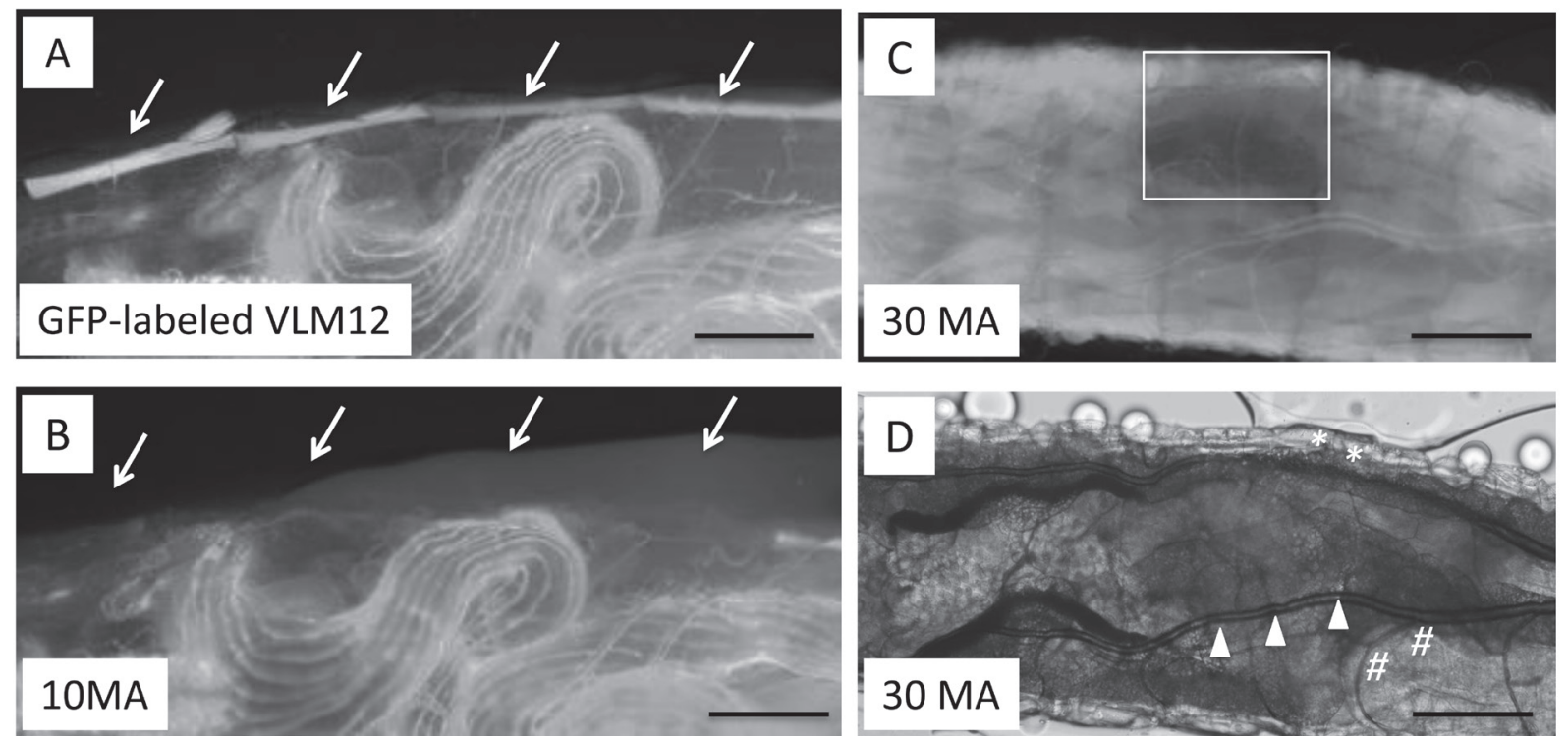

Fig. 1. Laser ablation of body wall results in increased trehalose levels. 10 muscle ablated (MA): Ten muscle fibers were lesioned using GFP signal as a guide to target ventrolateral body wall muscle 12 (VLM12). VLM12 is GFP labeled in 5053A-Gal4>UAS-2XEGFP (A, allows). Ablation was confirmed by the lack of GFP signal (arrows) (B). 30MA: Thirty muscle fibers, mostly in 1 or 2 abdominal segments, were ablated in EP6310>UAS-2XEGFP, which expresses GFP in all body muscles. Area where muscles were ablated is shown in box. (C). After the ablation, no apparent damages were found in the surrounding tissues: trachea (arrowheads), fat body (*), gut (\#) (D). Bars: $200 \mu \mathrm{m}$.

A

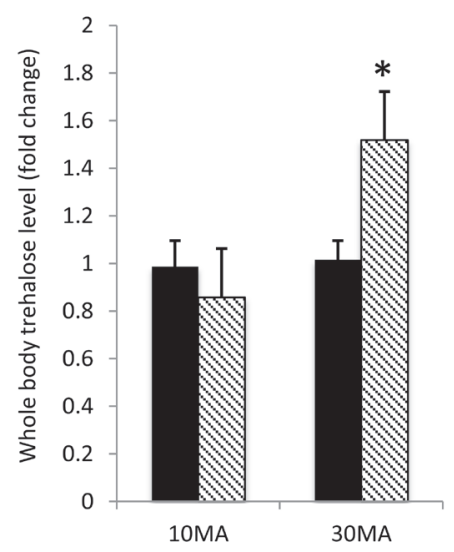

B

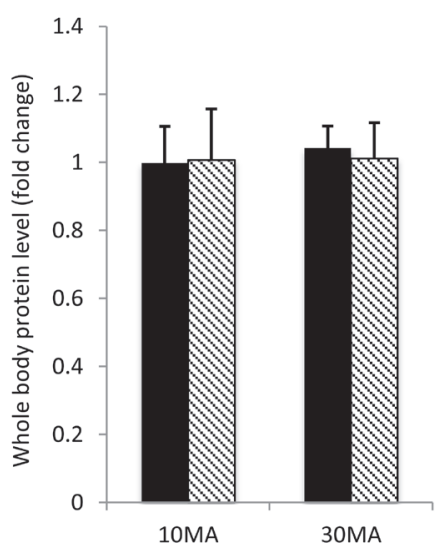

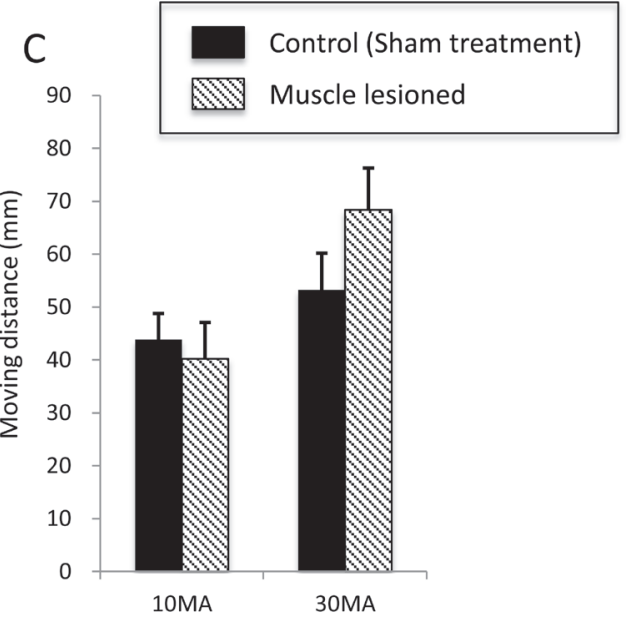

Fig. 2. Twenty-four hr after the ablation, the trehalose levels were significantly elevated. 10MA did cause any significant difference, but 30MA treatment resulted in increased overall trehalose level (A). *: $P<0.01$. In contrast, the protein levels were unchanged for either treatment. (B). The treatment did not affect locomotion activity. $P>0.68$ for $10 \mathrm{MA}$ muscle lesioned; $P>0.17$ for $30 \mathrm{MA}$ lesioned $(\mathrm{C})$. $\mathrm{n}=4,10 \mathrm{MA}$ control; $\mathrm{n}=5$, $10 \mathrm{MA} ; \mathrm{n}=5,30 \mathrm{MA}$ control; $\mathrm{n}=5,30 \mathrm{MA}$.

larvae were homogenized by vigorous shaking in the presence of Zirconia beads (NIKKATO Sakai Japan, $\varphi$ 0.8 YTZ Ball). The resultant homogenate was heated at $70^{\circ} \mathrm{C}$ for 5 $\mathrm{min}$. and centrifuged at 12,000 rpm for $5 \mathrm{~min}$. The resultant supernatant was used for subsequent measurements. Protein quantity was determined by Quant-iT ${ }^{\mathrm{TM}}$ Protein Assay Kits (Invitrogen, Carlsbad, CA, U.S.A.). Because the quantification of trehalose or protein determined here is that of lysate and reflects neither total nor hemolymph trehalose/protein. Therefore, we evaluated the metabolic abnormality by fold change. Similarly, locomotive activity was evaluated as follows: Twenty-four hr after the laser treatment, the larvae were placed on the grape juice plate. The locomotion activity was video recorded for $5 \mathrm{~min}$. The trajectory was measured on tracing film to quantify the distance that each larva traveled. All values are expressed as means $\pm \mathrm{SE}$. The statistical 
significance of differences was evaluated using student's test. Ablation of ten VLM12 fibers per larva mostly from A2 to A6 segments on both sides did not exert any prominent effect on metabolic and physical activities $24 \mathrm{hr}$ after the operation (Fig. 2). This may be because ten fibers merely correspond to less than $2 \%$ of total muscle amount. Therefore, next, we attempted to induce severe damage by targeting more muscle fibers in one or two segments. To achieve this, we screened several NP lines listed as ubiquitous body wall muscle Gal4 strains and identified NP6310 to be one of the most suitable strain for labeling muscles [10]. Lesioning of thirty muscle fibers in a few neighboring segments per larva (Fig. 1C), equivalent to ca. $5 \%$ of total muscle mass, resulted in increased whole-body trehalose levels (Fig. 2A). Although the physical activity was unchanged (Fig. 2C), the survival rate of laser-treated larva was $68 \%(n=31)$ in comparison to $82 \%(\mathrm{n}=51)$ for sham control, suggesting the increased sugar level is due to stress from physiological damage rather than dormant muscle activity. It is important to point out that we measured the trehalose levels of wholebody lysate instead of hemolymph trehalose because of technical difficulties to extract sufficient amount of hemolymph from the second instar larvae. Because the total volume of hemolymph in an adult fly is extremely small (ca. $0.1 \mu l$ ) [7], the contribution of any hemolymph trehalose to the total trehalose content can be regarded as negligible. Assuming that the total volume of hemolymph in larva is similar to that of an adult, the diabetic phenotype observed here may merely reflect the increased storage level of trehalose instead of "plasma" glucose. However, Broughton et al. reported the correlation between hemolymph and whole-body trehalose levels [2]. Therefore, similar to a mammalian system, the increased trehalose may indicate one of the stress response and potentially stress diabetes-like phenotype. Recently, isolation of hemolymph from a single fly was reported, which we hope will sophisticate the method and circumvent the issue here [8].

In the Drosophila genome, mammalian inflammatory cytokines, such as TNF, IL-1 and IL-6, are not encoded. However, the dopamine signaling is well conserved, and there are 70-90 dopaminergic neurons in fly larvae [29]. The aberrant dopamine signaling affects basal activity and locomotion similar to human Parkinson's disease. Because no difference was observed for locomotion activity in the muscle-ablated larvae, it is likely that dopamine signaling is not affected. Another possible hormonal mediator is ecdysone, which is a steroidal prohormone of the major insect molting hormone 20-hydroxyecdysone. Ecdysone levels sharply increase upon molting and metamorphosis [24]. In addition, ecdysone also plays an important role in egg formation, learning and sleep regulation [10, 17]. Furthermore, insulin and ecdysone are the critical extrinsic regulators of growth for the imaginal disks of insects [27]. Indeed, it is reported that ecdysone negatively regulates growth rates by impeding insulin signaling [4]. Therefore, laser-induced stress may have up-regulated ecdysone levels, resulting in reduced insulin activity.

In summary, to our knowledge, we showed for the first time that trauma or cellular damage leads to increased trehalose levels in Drosophila or insect larva. This could potentially provide a valuable opportunity to investigate the molecular and genetic bases of posttraumatic effect on the metabolism.

ACKNOWLEDGMENTS. We thank S. Kobayashi and Drosophila Genetic Resource Center in Kyoto for fly stocks.

\section{REFERENCES}

1. Bate, M. 1993. The mesoderm and its derivatives. pp.10131090. In: Dev. Drosoph. Melanogaster (Bate, M. and Arias, A. M. eds.), Cold Spring Harbor Laboratory Press, Cold Spring Harbor.

2. Broughton, S. J., Piper, M. D. W., Ikeya, T., Bass, T. M., Jacobson, J., Driege, Y., Martinez, P., Hafen, E., Withers, D. J., Leevers, S. J. and Partridge, L. 2005. Longer lifespan, altered metabolism, and stress resistance in Drosophila from ablation of cells making insulin-like ligands. Proc. Natl. Acad. Sci. U.S.A. 102: 3105-3110. [Medline] [CrossRef]

3. Campbell, L. V, Centre, D., Vincent, S. and Wales, S. 2006. Sick day management for patients with diabetes. Aust. Fam. Physician. 35: 405-406. [Medline]

4. Colombani, J., Bianchini, L., Layalle, S., Pondeville, E., Dauphin-Villemant, C., Antoniewski, C., Carré, C., Noselli, S. and Léopold, P. 2005. Antagonistic actions of ecdysone and insulins determine final size in Drosophila. Science 310: 667-670. [Medline] [CrossRef]

5. Cryer, P. E. 1994. Banting Lecture. Hypoglycemia: the limiting factor in the management of IDDM. Diabetes 43: 1378-1389. [Medline] [CrossRef]

6. Eakins, J. 2009. Blood Glucose Control in the Trauma Patient. $J$ Diabetes Sci. Technol. 3: 1373-1376. [Medline] [CrossRef]

7. Folk, D. G. and Bradley, T. J. 2004. The evolution of recovery from desiccation stress in laboratory-selected populations of Drosophila melanogaster. J. Exp. Biol. 207: 2671-2678. [Medline] [CrossRef]

8. Haselton, A. T. and Fridell, Y. W. 2011. Insulin injection and hemolymph extraction to measure insulin sensitivity in adult Drosophila melanogaster. J. Vis. Exp. pii: 2722. [Medline]

9. Hayashi, S., Ito, K., Sado, Y., Taniguchi, M., Akimoto, A., Takeuchi, H., Aigaki, T., Matsuzaki, F., Nakagoshi, H., Tanimura, T., Ueda, R., Uemura, T., Yoshihara, M. and Goto, S. 2002. GETDB, a database compiling expression patterns and molecular locations of a collection of Gal4 enhancer traps. Genesis 34: 58-61. [Medline] [CrossRef]

10. Ishimoto, H. and Kitamoto, T. 2011. Beyond molting-roles of the steroid molting hormone ecdysone in regulation of memory and sleep in adult Drosophila. Fly (Austin) 5: 215-220. [Medline] [CrossRef]

11. Lasko, P. 2002. Diabetic flies? Using Drosophila melanogaster to understand the causes of monogenic and genetically complex diseases. Clin. Genet. 62: 358-367. [Medline] [CrossRef]

12. Lee, G. and Park, J. H. 2004. Hemolymph sugar homeostasis and starvation-induced hyperactivity affected by genetic manipulations of the adipokinetic hormone-encoding gene in Drosophila melanogaster. Genetics 167: 311-323. [Medline] [CrossRef]

13. Lu, X. M., Hamrahi, V. F., Tompkins, R. G. and Fischman, A. J. 2009. Effect of insulin levels on the phosphorylation of specific amino acid residues in IRS-1: Implications for burn-induced insulin resistance. Int. J. Mol. Med. 24: 531-538. [Medline] 
14. Marik, P. E. and Bellomo, R. 2013. Stress hyperglycemia: an essential survival response! Crit. Care Med. 41: e93-e94. [Medline] [CrossRef]

15. Mecott, G. A., Al-Mousawi, A. M., Gauglitz, G. G., Herndon, D. N. and Jeschke, M. G. 2010. The role of hyperglycemia in burned patients: evidence-based studies. Shock 33: 5-13. [Medline] [CrossRef]

16. Mester, M., Carter, E. A., Tompkins, R. G., Gelfand, J. A., Dinarello, C. A., Burke, J. F. and Clark, B. D. 1994. Thermal injury induces very early production of interleukin-1 alpha in the rat by mechanisms other than endotoxemia. Surgery 115: 588-596. [Medline]

17. Morris, L. X. and Spradling, A. C. 2012. Steroid signaling within Drosophila ovarian epithelial cells sex-specifically modulates early germ cell development and meiotic entry. PLOS ONE 7: e46109. [Medline] [CrossRef]

18. Mortimer, N. T. and Moberg, K. H. 2013. The archipelago ubiquitin ligase subunit acts in target tissue to restrict tracheal terminal cell branching and hypoxic-induced gene expression. PLoS Genet. 9: e1003314. [Medline] [CrossRef]

19. Rajan, A. and Perrimon, N. 2012. Drosophila cytokine unpaired 2 regulates physiological homeostasis by remotely controlling insulin secretion. Cell 151: 123-137. [Medline] [CrossRef]

20. Rajan, A. and Perrimon, N. 2013. Of flies and men: insights on organismal metabolism from fruit flies. BMC Biol. 11: 38 . [Medline]

21. Rayfield, E. J., Curnow, R. T., George, D. T. and Beisel, W. R. 1973. Impaired carbohydrate metabolism during a mild viral illness. N. Engl. J. Med. 289: 618-621. [Medline] [CrossRef]

22. Ritzenthaler, S., Suzuki, E. and Chiba, A. 2000. Postsynaptic filopodia in muscle cells interact with innervating motoneuron axons. Nat. Neurosci. 3: 1012-1017. [Medline] [CrossRef]

23. Rulifson, E. J., Kim, S. K. and Nusse, R. 2002. Ablation of insulin-producing neurons in flies: growth and diabetic phenotypes. Science 296: 1118-1120. [Medline] [CrossRef]

24. Spindler, K. D., Hönl, C., Tremmel, C., Braun, S., Ruff, H. and Spindler-Barth, M. 2009. Ecdysteroid hormone action. Cell. Mol. Life Sci. 66: 3837-3850. [Medline] [CrossRef]

25. Taylor, F., Levenson, S. and Adams, M. 1944. Abnormal carbohydrate metabolism in human thermal burns. N. Engl. J. Med. 231: 437-445. [CrossRef]

26. Thomsen, V. 1938. Studies in trauma and carbohydrate metabolism with special reference to the existence of traumatic diabetes. Acta Med. Scand. 96: 1-416.

27. Tobler, A. and Nijhout, H. F. 2010. A switch in the control of growth of the wing imaginal disks of Manduca sexta. PLOS ONE 5: e10723. [Medline] [CrossRef]

28. van den Berghe, G., Wouters, P., Weekers, F., Verwaest, C., Bruyninckx, F., Schetz, M., Vlasselaers, D., Ferdinande, P., Lauwers, P. and Bouillon, R. 2001. Intensive insulin therapy in critically ill patients. N. Engl. J. Med. 345: 1359-1367. [Medline] [CrossRef]

29. Xiu, F., Stanojcic, M., Diao, L. and Jeschke, M. G. 2014. Stress hyperglycemia, insulin treatment, and innate immune cells. Int. J. Endocrinol. 2014: 486403. [Medline] [CrossRef]

30. Yamamoto, S. and Seto, E. S. 2014. Dopamine dynamics and signaling in Drosophila: an overview of genes. Exp. Anim. 63: 107-119. [Medline] [CrossRef]

31. Yendamuri, S., Fulda, G. J. and Tinkoff, G. H. 2003. Admission hyperglycemia as a prognostic indicator in trauma. J. Trauma 55: 33-38. [Medline] [CrossRef]

32. Zhang, Q., Carter, E. A., Ma, B. Y., White, M., Fischman, A. J. and Tompkins, R. G. 2005. Molecular mechanism(s) of burninduced insulin resistance in murine skeletal muscle: role of IRS phosphorylation. Life Sci. 77: 3068-3077. [Medline] [CrossRef] 